\title{
ENVIRONMENTAL AND ANTHROPIC CONTROLS ON SEDIMENTS AND BIOMARKER DEPOSITION IN A DECANTATION TANK (ORLEANS, FRANCE)
}

J. Jacob ${ }^{1}$, A. Simonneau ${ }^{2}$, A. Thibault ${ }^{2}$, T. Thiebault ${ }^{3}$, C. Le Milbeau ${ }^{2}$, R. Boscardin ${ }^{2}$, L. Fougère $^{4}$, E. Destandau ${ }^{4}$, C. Morio ${ }^{5}$

${ }^{1}$ Laboratoire des Sciences du Climat et de l'Environnement, France

${ }^{2}$ Institut des Sciences de la Terre d'Orléans, France

${ }^{3}$ Milieux environnementaux, transferts et interactions dans les hydrosystèmes et les sols, France

${ }^{4}$ Institut de Chimie Organique et Analytique, France

${ }^{5}$ Orléans métropole, France

\section{Introduction}

Human activities are being registered by an unprecedented variety and concentration of markers in the sedimentary record. This is the founding concept of the Anthropocene for which a lower boundary was set at 1945 (Zalasiewicz et al., 2016) and a Global Boundary Stratotype Section and Point (GSSP) is currently under examination (Waters et al., 2018). Within the Golden Spike project (BIOHEFECT-EC2CO, CNRS-INSU) we propose that sedimentary archives deposited in sewer networks of urban areas constitute targets for Anthropocene GSSP because they are susceptible of recording a high diversity of concentrated matters, elements, biomarkers and isotopes of human origin through time. Before exploring such sediments, we investigate their potential as archives, i.e. the factors affecting their deposition processes, the availability of pertinent tracers and the controls on their archivability.

\section{Results}

Sediments are stratigraphically organized and two main facies have been identified in both cores: (1) organic sediments (TOC $>2 \%$ ) with fine-grained mineral particles dominating the lower section and (2) mineral sediments with coarser grains in the upper section. By comparison with meteorological data and chronological constrains on sediment deposition $\left({ }^{7} \mathrm{Be}\right)$, these facies could be attributed to the respective contributions of stormwater and wastewater inputs. During rain episodes, roads and sidewalks are washed and bring coarse and mineral particles to the tank whereas during dry days, sediment is essentially built from organic materials carried by the wastewater. Other markers identified in the sediments confirm these assertions. Glass microsphere that originate from road paintings are for example abundant in mineral sediments and rare in the organic ones. Reversely and evidently, bile acids are rather concentrated in organic facies but diluted in the mineral ones. The picture is different for drugs and illicit drugs. For example, cocaine was detected in mineral sediments but not in organic facies, whereas carbamazepine was found in all the section but more abundant in the organicrich part. Both these compounds are transported by wastewater. Hence, superimposed on the respective delivery of biomarkers from wastewater and stormwater, the affinity of these biomarkers for distinct bearing phases, due to their speciation, constitutes a major control on their archiving. 


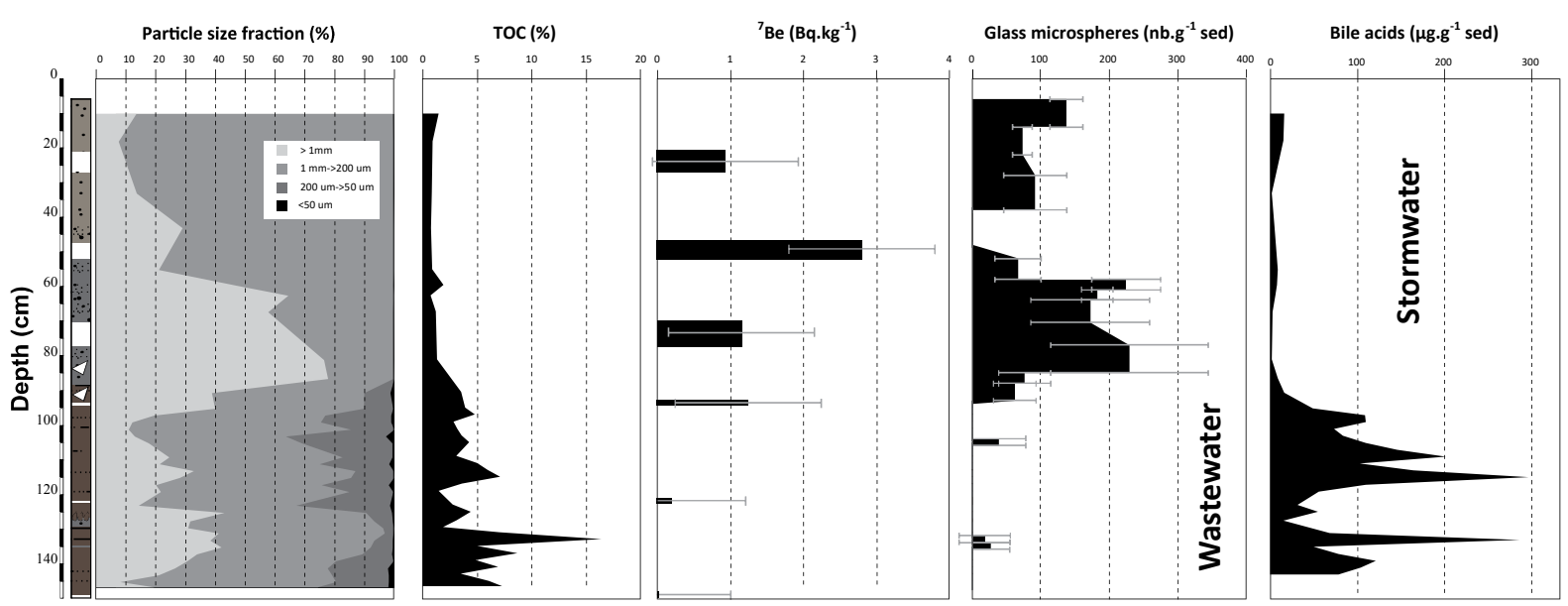

Figure 1 Evolution of particle size fraction, Total Organic Carbon, ${ }^{7}$ Be, glass microspheres and bile acids concentrations in core CSA-03/2016-5.

\section{Conclusions}

Sediments accumulated in sewer networks constitute potential targets to reconstruct the recent history of human activities. They are stratigraphically organised, as are sediments in more natural environments, and are responsive to respective contributions from wastewater and stormwater depending on precipitation events. These sediments afford an impressive range of anthropic biomarkers, the distribution of which is not only controlled by the amount released by the population, but also by the nature of sediments with which they interact.

\section{References}

Waters et al., 2018. Global Boundary Stratotype Section and Point (GSSP) for the Anthropocene Series: Where and how to look for potential candidates. Earth-Science Reviews 178, 379-429. 